\title{
Influence of Molecular Design on the Targeting Properties of ABD-Fused Mono- and Bi-Valent Anti-HER3 Affibody Therapeutic Constructs
}

\author{
Mohamed Altai ${ }^{1,2, *,+}$, Charles Dahlsson Leitao ${ }^{3,+}$, Sara S. Rinne ${ }^{2}$, Anzhelika Vorobyeva ${ }^{1(D)}$ \\ Christina Atterby ${ }^{1}$, Stefan Ståhl ${ }^{3}$, Vladimir Tolmachev ${ }^{1} \mathbb{D}$, John Löfblom ${ }^{3} \mathbb{D}$ and \\ Anna Orlova 2,4 (i) \\ 1 Department of Immunology, Genetics and Pathology, Uppsala University, 75185 Uppsala, Sweden; \\ anzhelika.vorobyeva@igp.uu.se (A.V.); christina.atterby@igp.uu.se (C.A.); \\ Vladimir.tolmachev@igp.uu.se (V.T.) \\ 2 Department of Medicinal Chemistry, Uppsala University, 75123 Uppsala, Sweden; \\ sara.rinne@ilk.uu.se (S.S.R.); anna.orlova@ilk.uu.se (A.O.) \\ 3 Department of Protein Science, School of Engineering Sciences in Chemistry, Biotechnology and Health, \\ KTH Royal Institute of Technology, 10691 Stockholm, Sweden; chdl@kth.se (C.D.L.); \\ stefans@biotech.kth.se (S.S.); lofblom@kth.se (J.L.) \\ 4 Science for Life Laboratory, Uppsala University, 75237 Uppsala, Sweden \\ * Correspondence: Mohamed.altai@igp.uu.se; Tel.: +46-18-471-3414; Fax: +46-18-471-3432 \\ + These authors contributed equally to this work.
}

Received: 1 September 2018; Accepted: 8 October 2018; Published: 11 October 2018

check for updates

\begin{abstract}
Overexpression of human epidermal growth factor receptor type 3 (HER3) is associated with tumour cell resistance to HER-targeted therapies. Monoclonal antibodies (mAbs) targeting HER3 are currently being investigated for treatment of various types of cancers. Cumulative evidence suggests that affibody molecules may be appropriate alternatives to mAbs. We previously reported a fusion construct (3A3) containing two HER3-targeting affibody molecules flanking an engineered albumin-binding domain $\left(\mathrm{ABD}_{035}\right)$ included for the extension of half-life in circulation. The 3A3 fusion protein $(19.7 \mathrm{kDa})$ was shown to delay tumour growth in mice bearing HER3-expressing xenografts and was equipotent to the $\mathrm{mAb}$ seribantumab. Here, we have designed and explored a series of novel formats of anti-HER3 affibody molecules fused to the ABD in different orientations. All constructs inhibited heregulin-induced phosphorylation in HER3-expressing BxPC-3 and DU-145 cell lines. Biodistribution studies demonstrated extended the half-life of all ABD-fused constructs, although at different levels. The capacity of our ABD-fused proteins to accumulate in HER3-expressing tumours was demonstrated in nude mice bearing BxPC-3 xenografts. Formats where the $\mathrm{ABD}$ was located on the C-terminus of affibody binding domains (3A, 33A, and 3A3) provided the best tumour targeting properties in vivo. Further development of these promising candidates for treatment of HER3-overexpressing tumours is therefore justified.
\end{abstract}

Keywords: HER3; affibody; molecular design; therapy

\section{Introduction}

Extensive research over the last decades has led to a better understanding of tumour biology and specific mechanisms of cancer development [1]. It has been demonstrated that cancer hallmarks such as resistance to apoptosis, invasiveness, and high proliferative rate are regulated and controlled by a sophisticated intracellular system of signalling cascades. These signalling pathways are often triggered by aberrantly expressed surface receptors such as receptor tyrosine kinases (RTKs). RTKs 
are transmembrane receptors sub-classified into 17 different classes that all have an intracellular domain that activates cellular downstream signalling pathways after interaction of the extracellular domain with an appropriate ligand [2]. Growth factors, cytokines, and hormones serve as natural ligands for receptor activation. Dysregulation of any element in the ligand-receptor-signalling chain can be a driving force in sustaining signalling. Advancements in our understanding of the mechanisms underlying cancer hallmarks have led to the design and development of a new class of anti-cancer drugs that are more cancer-specific. They are based on targeting of particular elements in the ligand-receptor-signalling chain. Monoclonal antibodies (mAbs) constitute the most well-studied class of targeting drugs. Today over 50 antibodies are approved by the US Food and Drug Administration (FDA), and many more are under development [3]. Many of these approved mAbs are directed against cancer. The mechanisms of action of $\mathrm{mAbs}$ as anti-cancer agents include: preventing ligand-receptor interactions (e.g., bevacizumab, which blocks vascular endothelial growth factor (VEGF) from binding to receptors), downregulating receptor expression (e.g., trastuzumab for treatment of human epidermal growth factor receptor type 2 (HER2)-positive tumours), preventing receptor dimerization (e.g., pertuzumab), and recruitment of the endogenous immune system (for example through activation of antibody-dependent cell-mediated cytotoxicity (ADCC)). In addition, mAbs can be utilized as vehicles to deliver toxic payloads to targeted cells [4].

Human epidermal growth factor receptor type 3 (HER3), an RTK belonging to the HER family, is a key player in many types of cancers. Enhanced expression of these receptors correlates with poor prognosis and disease progression [5,6]. Today, there are no approved protein-based drugs specifically targeting HER3. Currently, two mAbs (patrimumab and seribantumab) are being evaluated in late-phase clinical trials for treatment of several HER3-expressing cancers (National Clinical Trials: NCT02134015, NCT02387216). However, mAbs are not in all cases ideal for therapeutic applications. For example, the large size of $\mathrm{mAbs}$ hampers efficient extravasation and reduces tissue penetration, and stability issues sometimes occur [7]. Moreover, $\mathrm{mAb}$ production is challenging and expensive (especially in terms of good manufacturing practice compliance).

One possible alternative to $\mathrm{mAbs}$ is the use of engineered scaffold proteins (ESPs) [8]. ESPs are sometimes referred to as antibody-mimetics where the scaffold protein is composed of a constant region (which stabilizes the overall protein folding) and variable regions that mediate its binding to a specific target. Several features of non-immunoglobulin-based scaffolds might be attractive for drug applications: robust structure, defined chemical composition, small size, multimerization possibilities, and relatively low production costs [9-11]. Moreover, available clinical reports have clearly demonstrated the safety, low immunogenicity, and efficacy of ESP-based therapeutics [12]. Many ESPs permit high production yield in bacterial expression systems. Over 50 different scaffolds have been reported within the last two decades; however, only a limited number of them have undergone thorough development [12].

Affibody molecules are developed by combinatorial protein engineering of the 58-residue (molecular weight $(\mathrm{MW}) \approx 7 \mathrm{kDa}$ ) protein A-derived $\mathrm{Z}$ domain [13,14]. This class of targeting agents has been successfully evaluated in the clinic for molecular recognition in both diagnostic and therapeutic applications. Affibody-based HER2 binders have been used in the clinic for visualization of HER2 expression in metastatic breast cancer [15,16], C5 complement binders have been used for treatment of inflammatory diseases (NCT02083666), and interleukin-17A (IL-17A) binders have been used for treatment of psoriasis (NCT02690142). So far, the accumulated evidence from these clinical trials suggests affibody molecules to be efficacious and safe in humans.

We have reported the selection of an anti-HER3 affibody molecule with affinities to HER3 in the picomolar range [17]. It was demonstrated that anti-HER3 affibody molecules blocked binding of the natural ligand heregulin and the anti-HER3 antibody seribantumab, suggesting that the affibody recognized an overlapping epitope on the receptor [18-21]. Moreover, it also inhibited heregulin-induced cancer cell growth in vitro by suppressing phosphorylation [18]. A common observation from biodistribution studies of radiolabelled anti-HER3 affibody molecules was the rapid 
clearance from the blood via kidneys [22]. This is typical for affibody molecules as they have a size below the kidney cut-off $(<60 \mathrm{kDa})$ [11]. One strategy to extend in vivo half-life is based on genetic fusion of affibody molecules to an engineered albumin-binding domain (ABD) [23]. $\mathrm{ABD}_{035}$ (46 amino acids, $\mathrm{MW} \approx 5.2 \mathrm{kDa}$ ) binds to human serum albumin with femtomolar affinity [24]. ABD-mediated half-life extension has been explored for affibody molecules, antibody fragments, and peptides, and has efficiently increased the plasma half-life of fused conjugates up to around the half-life that is reported for endogenous albumin (i.e., around $30 \mathrm{~h}$ in mice and 12-17 days in humans) with no immunogenicity issues $[11,23,25]$.

It has been proposed that multivalent constructs could provide increased therapeutic potential compared to monomeric analogues. Indeed, in vitro the bi- and trivalent HER3-specific affibody molecules were significantly more efficient in blocking phosphorylation of HER3 and inhibiting cellular activity and proliferation compared to the monovalent control $[20,26]$. We demonstrated that a bivalent construct based on an anti-HER3 affibody molecule fused with ABD, 3A3, also efficiently inhibited growth of HER3-expressing cells in vitro, had prolonged in vivo half-life, delayed growth of HER3-expressing BxPC-3 xenografts in mice, and was equipotent to seribantumab (MM-121) [27,28]. Importantly there was no observable toxicity after multiple administrations of the construct [28].

Earlier studies have demonstrated a strong influence of molecular design (sequence of binding domains, valency, composition of linkers and termini) on in vivo targeting and biodistribution properties of targeting agents [29-32]. Dependent on design, constructs might interact differently with targeted as well as non-targeted tissues. Careful optimization of the molecular design may therefore help to find drugs with desired properties. Such effects become additionally important when the drug efficacy depends on binding to two different targets synchronously. We therefore hypothesized that the relative position of the building molecular blocks of the ABD-fused HER3-targeting affibody molecules (i.e., HER3-binding affibody and albumin-binding moiety) may have a profound influence on targeting properties. In the present study, we have designed and explored a series of novel formats of anti-HER3 affibody molecules flanking ABD using similar molecular blocks: anti-HER3 affibody molecule $Z_{H E R 3: 08698}$, albumin-targeting $A_{B B D_{035}}$, and a $G_{3} S$ linker. We included five constructs with one or two HER3-targeting arms fused to ABD with different orientations (Figure 1): two monovalent constructs, $Z_{\mathrm{HER} 3: 08698}-\mathrm{G}_{3} \mathrm{~S}-\mathrm{ABD}_{035}$ and $\mathrm{ABD}_{035}-\mathrm{G}_{3} \mathrm{~S}-\mathrm{Z}_{\mathrm{HER} 3: 08698}$ (designated as $3 \mathrm{~A}$ and $\mathrm{A} 3$, respectively), and three bivalent constructs, $Z_{\mathrm{HER} 3: 08698}-Z_{\mathrm{HER3}: 08698}-\mathrm{G}_{3} \mathrm{~S}-\mathrm{ABD}_{035}$, $\mathrm{Z}_{\mathrm{HER3}: 08698}-\mathrm{G}_{3} \mathrm{~S}-\mathrm{ABD}_{035}-\mathrm{G}_{3} \mathrm{~S}-\mathrm{Z}_{\mathrm{HER} 3: 08698}$, and $\mathrm{ABD}_{035}-\mathrm{G}_{3} \mathrm{~S}-\mathrm{Z}_{\mathrm{HER} 3: 08698}-\mathrm{Z}_{\mathrm{HER} 3: 08698}$ (designated as 33A, $3 \mathrm{~A} 3$, and $\mathrm{A} 33$, respectively). For investigation of in vitro and in vivo targeting and biodistribution, all constructs were site-specifically conjugated with a 1,4,7,10-tetraazacyclododecane-1,4,7,10-tetraacetic acid (DOTA) chelator and radiolabelled with the residualizing radionuclide ${ }^{111}$ In. For simplicity, the DOTA-conjugated constructs are further designated as $3 \mathrm{~A}, \mathrm{~A} 3,33 \mathrm{~A}, 3 \mathrm{~A} 3$, and $\mathrm{A} 33$.

It is important to mention that the bivalent construct $3 \mathrm{~A} 3$ used in the current study comprises similar molecular blocks to those reported by Bass et al. [27]. However, the newly designed construct used in this study differs in that a shorter $\mathrm{G}_{3} \mathrm{~S}$ linker is used between the binding moieties. Shorter linker lengths have the potential to result in higher production yields and lower susceptibility to serum proteases. This makes $3 \mathrm{~A} 3$ a very similar but slightly smaller bivalent construct compared to the previously reported variant.

Our results reveal that the relative position of the building molecular blocks of the ABD-fused HER3-targeting affibody molecules has an impact on internalization rate, half-life in blood, and tumour targeting. 


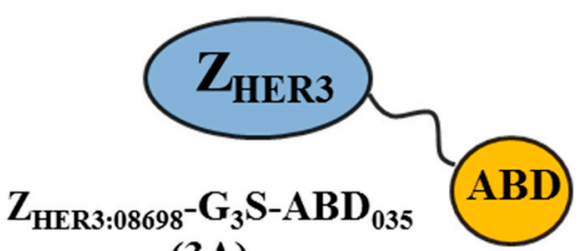

(3A)

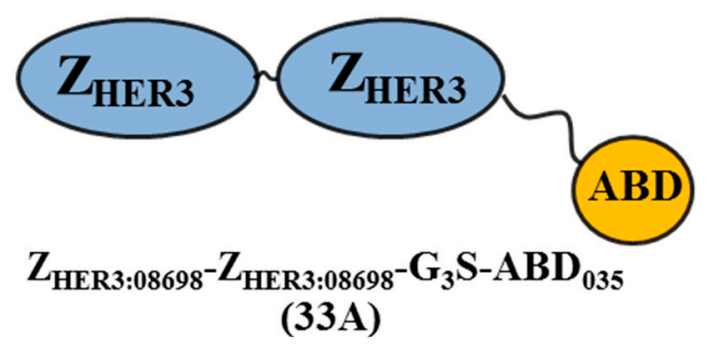

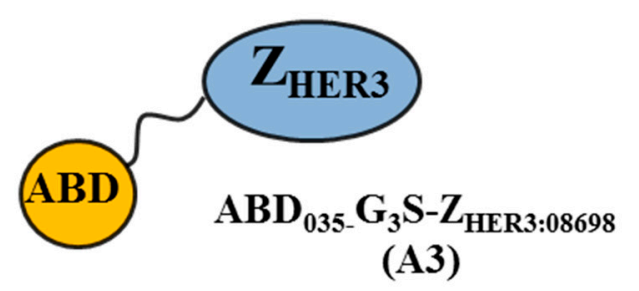

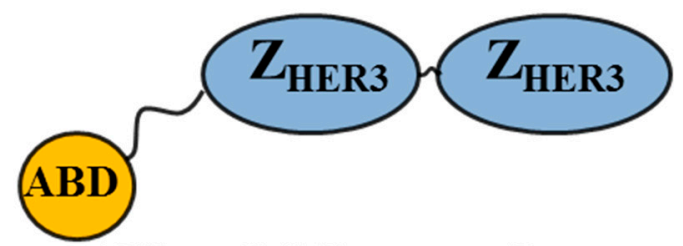

$\mathrm{ABD}_{035}-\mathrm{G}_{3} \mathrm{~S}-\mathrm{Z}_{\mathrm{HER3}: 08698}-\mathrm{Z}_{\text {HER3:08698 }}$ (A33)

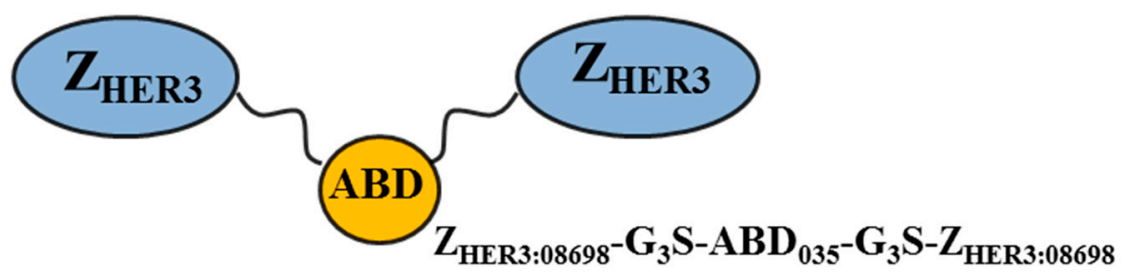

(3A3)

Figure 1. Schematic representation of anti-HER3 affibody molecules flanking ABD with different orientations. ABD: albumin-binding domain; HER3: human epidermal growth factor receptor type 3.

\section{Materials and Methods}

\subsection{Production of Constructs, Chelator Conjugation, and Product Purification}

Genes for the five constructs were synthesized and subcloned into a pET26b(+) vector (Thermo Scientific, Chicago, IL, USA). The plasmids were transformed into BL21*(DE3) Escherichia coli (E. coli) (Thermo Fisher Scientific, Chicago, IL, USA) using a standard heat-shock protocol. Protein production proceeded overnight at $25^{\circ} \mathrm{C}$ after induced expression with $100 \mu \mathrm{M}$ isopropyl $\beta$-D-1-thiogalactopyranoside (IPTG) at an optical density measured at a wavelength of $600 \mathrm{~nm}\left(\mathrm{OD}_{600}\right)$ of 0.8 . Following cell lysis with French press, the proteins were recovered with affinity chromatography using human serum albumin (HSA) immobilized to Sepharose matrix as a ligand. TST buffer ( $25 \mathrm{mM}$ Tris-HCl, $1 \mathrm{mM}$ EDTA, $200 \mathrm{mM} \mathrm{NaCl}, 0.05 \%$ Tween, $\mathrm{pH}$ 8.0) was used as running buffer, with ammonium acetate $(5 \mathrm{mM}, \mathrm{pH} 5.5)$ for washing followed by elution with acetic acid ( $0.5 \mathrm{M}, \mathrm{pH} 2.8)$ and subsequent freeze-drying.

The freeze-dried proteins were dissolved in ammonium acetate $(20 \mathrm{mM}, \mathrm{pH} 5.5)$ and reduced with a molar concentration of TCEP (tris(2-carboxyethyl)phosphine) equal to the protein concentration for $30 \mathrm{~min}$ at $37^{\circ} \mathrm{C}$. The proteins were incubated at $37^{\circ} \mathrm{C}$ for 90 min with a 10 -fold molar excess of maleimide-DOTA (CheMatech, Dijon, France) for site-specific conjugation to a C-terminal cysteine on the constructs. Reverse-phase high performance liquid chromatography (RP-HPLC) (Agilent Technologies, Santa Clara, CA, USA) was used for purification following DOTA-conjugation as described previously [27]. 


\subsection{Characterization of the Conjugated Proteins}

The purity of the constructs was determined using RP-HPLC and an analytical Zorbax 300SB-C18 column (Agilent Technologies, Santa Clara, CA, USA) with a $25-45 \%$ acetonitrile elution gradient over $20 \mathrm{~min}$ with a flow rate of $1 \mathrm{~mL} / \mathrm{min}$.

Circular dichroism spectroscopy was performed using a Chirascan spectropolarimeter (Applied Photophysics, Surrey, UK) with an optical path length of $1 \mathrm{~mm}$ in order to analyse the alpha-helical content, thermal stability, and refolding capacity of the constructs at a concentration of $0.25 \mathrm{mg} / \mathrm{mL}$. The thermal stability was evaluated by measuring the change in ellipticity at $221 \mathrm{~nm}$ during heating $\left(5^{\circ} \mathrm{C} / \mathrm{min}\right.$ ) from 20 to $90^{\circ} \mathrm{C}$. The melting temperatures $\left(\mathrm{T}_{\mathrm{m}}\right)$ were approximated from the data acquired from variable temperature measurements (VTM) by curve fitting using a Boltzmann Sigmoidal model (GraphPad Prism, version 7, GraphPad Software, La Jolla, CA, USA). The refolding capacity was assessed by comparing spectra obtained from measurements at wavelengths in the range of $195-260 \mathrm{~nm}$ at $20^{\circ} \mathrm{C}$, before and after thermal denaturation.

Electrospray ionization mass spectrometry (ESI-MS) with a 6520 Accurate-Mass Q-TOF LC/MS apparatus (Agilent Technologies) was used for confirmation of the molecular masses of the purified constructs.

\subsection{Affinity Determination}

The concomitant binding of the constructs to human HER3 (Sino Biological, Wayne, PA, USA) was investigated with a capture setup on a BIAcore T200 system (GE Healthcare, Princeton, NJ, USA) using a CM5 sensor chip with three immobilization levels of HSA (two surfaces with 550 response units (RU) and one with $2000 \mathrm{RU}$ ). The constructs were captured on the surfaces whereupon HER3 was injected in a multi-cycle setup using five concentrations of $\operatorname{HER} 3(3.125,6.25,12.5,25$, and $50 \mathrm{nM})$. The acquired sensorgrams were analysed using a Langmuir 1:1 kinetic model. In addition, the binding affinity to HSA was investigated, using the same sensor chip and multi-cycle setup. Four concentrations of the constructs $(1.5625,3.125,6.25$, and $12.5 \mathrm{nM})$ were injected in duplicates and allowed to dissociate from the surface. The sensorgrams acquired from the surface immobilized with $2000 \mathrm{RU}$ were analysed using a Langmuir 1:1 kinetic model.

\subsection{Radiolabelling of Constructs with Indium-111 and Stability Test of Radiolabelled Constructs}

${ }^{111}$ In-indium chloride was purchased from Covidien (Petten, The Netherlands). High-quality Milli-Q water (resistance higher than $18 \mathrm{M} \Omega / \mathrm{cm}$ ) was used for preparing solutions. To work in metal free conditions the buffers were purified and incubated with Chelex 100 resin (Bio-Rad Laboratories, Hercules, CA, USA) overnight. Radiolabelling of the constructs with ${ }^{111}$ In was completed according to a previously reported protocol adapted from Bass et al. [27]. Labelling yields were measured using silica-impregnated glass fibre sheets for instant Thin Layer Chromatography (iTLC) with a $0.2 \mathrm{M}$ citric acid mobile phase. Conjugates were purified from any non-bound ${ }^{111} \mathrm{InCl}_{3}$ by using size exclusion NAP-5 columns (GE-Healthcare, Uppsala, Sweden) preequilibrated with phosphate buffered saline (PBS).

To evaluate the labelling stability of the labelled constructs, an EDTA-challenge test was performed. Two samples of each radiolabelled construct were diluted with a 500-fold molar excess of the disodium salt of EDTA in water. The samples were kept at room temperature and after $1 \mathrm{~h}$ incubation all samples were analysed using radio-iTLC.

\subsection{In Vitro Studies}

The HER3-expressing human cell lines BxPC-3 (primary pancreatic adenocarcinoma), DU-145 (human prostate cancer), MCF-7 (breast cancer cell line), and LS-174T (colon cancer) were used (American Type Culture Collection, ATCC via LGC Promochem, Borås, Sweden). The cells were cultured in Roswell Park Memorial Institute (RPMI) medium (Flow, Irvine, UK) supplemented with 
$10 \%$ foetal bovine serum (Sigma-Aldrich, St. Louis, MO., USA), $2 \mathrm{mM}$ L-glutamine, and a mixture of penicillin $100 \mathrm{IU} / \mathrm{mL}$ and $100 \mu \mathrm{g} / \mathrm{mL}$ streptomycin (PEST, Biokrom Kg, Berlin, Germany). HER3 expression for MCF-7 and DU-145 cells was measured using the same method as for BxPC-3 and LS-174T [21].

\subsection{Inhibition of Phosphorylation}

A human Phospho-HER3 ELISA assay was performed on BxPC-3 and DU145 cells according to a previously published protocol [28]. To prepare samples for the ELISA assay, cells were treated with the affibody constructs $\left(200 \mathrm{nM}, 10 \mathrm{~min}\right.$ at $37^{\circ} \mathrm{C}$ ). Starvation media was used to equalize volume in positive and negative controls. Thereafter, $4 \mathrm{nM}$ of heregulin was added to the dishes containing the affibody construct and to the positive control; starvation media was added to the negative control. After incubation for $10 \mathrm{~min}$ at $37^{\circ} \mathrm{C}$ cells were placed on ice, media was removed, and cells were washed twice in ice-cold PBS. Cells were incubated for $5 \mathrm{~min}$ on ice with $400 \mu \mathrm{L}$ of lysis buffer $(20 \mathrm{mM}$ Tris-HCl, $150 \mathrm{mM} \mathrm{NaCl}, 1 \mathrm{mM} \mathrm{Na} 2$ EDTA, $1 \mathrm{mM}$ EGTA, $1 \%$ Triton $2.5 \mathrm{mM}$ sodium pyrophosphate, $1 \mathrm{mM}$ $\beta$-glycerophosphate, $1 \mathrm{mM} \mathrm{Na} \mathrm{VO}_{4}$, and $1 \mu \mathrm{g} / \mathrm{mL}$ leuceptin (Cell Signaling Technology, Danvers, MA, USA)), additionally supplied with $1 \mathrm{mM}$ activated sodium orthovanadate (BioVision, City, CA, USA) and phosphatase inhibitor cocktail (Roche, Mannheim, Germany). The lysed cells were scraped from the dish, collected, and sonicated for $45 \mathrm{~s}$, before being centrifuged for $10 \min \left(14,000 \mathrm{rpm}, 4{ }^{\circ} \mathrm{C}\right)$. The supernatant was collected and used in the Phospho-HER3 ELISA.

A Human Phospho-ErbB3/HER3 ELISA kit (DuoSet $\left.{ }^{\circledR} I C\right)$ was purchased from R\&D Systems (R\&D Systems, Inc., Minneapolis, MN, USA) and used according to manufacturer's instructions. Briefly, 96-well plates were coated with capture antibody $(4 \mu \mathrm{g} / \mathrm{mL}$ in PBS) and incubated overnight. All incubations were done at room temperature. Wells were washed with $0.05 \%$ Tween ${ }^{\circledR} 20$ (Sigma-Aldrich, St. Louis, MOCity, USA) in PBS and blocked with 1\% bovine serum albumin (BSA) in PBS for $2 \mathrm{~h}$. Thereafter, $100 \mu \mathrm{L}$ of respective cell lysate was added to each well in quadruplicates. The plate was incubated for $2 \mathrm{~h}$, aspirated, washed and anti-phospho-tyrosine-HRP diluted in $0.05 \%$ Tween ${ }^{\circledR 20}, 1 \%$ BSA in PBS after manufacturer's instruction was added. After $2 \mathrm{~h}$ the wells were washed and $100 \mu \mathrm{L}$ substrate solution (1:1 mixture of $\mathrm{H}_{2} \mathrm{O}_{2}$ and tetramethylbenzidine, $\mathrm{R} \& D$ systems) was added to the wells. Following $15 \mathrm{~min}$ of incubation (protected from direct light) the reaction was stopped by adding $50 \mu \mathrm{L} \mathrm{H}_{2} \mathrm{~S}_{4}(1 \mathrm{M})$. Absorption in each well was measured at $450 \mathrm{~nm}$.

\subsection{In Vitro Specificity}

The specificity of the HER3 affibody ABD-fused conjugates was tested on BxPC-3 and DU-145 cells in vitro. A $100 \mathrm{pM}$ solution of each radiolabelled conjugate was added to a set of cell dishes (ca. $1 \times 10^{6}$ cells/dish, $35 \mathrm{~mm}, n=3$ ). For blocking, an excess of the non-radiolabelled anti-HER3

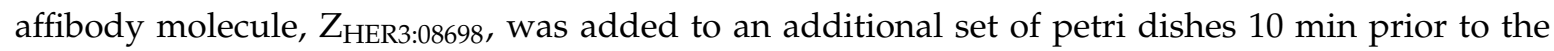
addition of the respective conjugate. Cells were then treated as described in detail previously $[27,28]$.

\subsection{Cellular Processing and Internalization}

To compare the internalization rate of labelled constructs by different cell lines (BxPC-3, DU145, LS174T, and MCF-7), a continuous incubation method, developed earlier, was used [33]. Briefly, $1 \times 10^{6}$ cells/dish $(n=3)$ were incubated with $100 \mathrm{pM}$ of the respective radiolabelled compounds at $37^{\circ} \mathrm{C}$, in $5 \% \mathrm{CO}_{2}$. At predetermined time points after the start of incubation, cells in three dishes were analysed for membrane-bound as well as internalized radioactivity. All activity fractions were measured in an automated $\gamma$-spectrometer.

\subsection{In Vivo Studies}

All animal experiments were planned and performed in accordance with national legislation on laboratory animals' protection and were approved by the Ethics Committee for Animal Research in Uppsala, Sweden (animal permission C143/14, approved 16 September 2014). 
Comparative biodistribution studies were performed in female Balb/c nu/nu mice. Mice were implanted with BxPC-3 $\left(5 \times 10^{6}\right.$ cells $)$ in the left hind leg three weeks prior to the start of the experiment. The average animal weight was $19 \pm 1 \mathrm{~g}$, and the average tumour weight was $0.3 \pm 0.1 \mathrm{~g}$ at the start of the experiment. Mice were sorted into five groups $(n=12)$. Each group of animals was injected intravenously with the corresponding radiolabelled anti-HER3 construct. The injected activity was $20 \mathrm{kBq} /$ mouse (100 $\mu \mathrm{L} 2 \%$ BSA in PBS containing 100-fold molar excess EDTA). The injected protein dose was 2 nmole: $40 \mu \mathrm{g} /$ mouse for bivalent 33A, 3A3, and A33, and $26 \mu \mathrm{g} /$ mouse for monovalent $3 \mathrm{~A}$ and $\mathrm{A} 3$. At predetermined time points (1,4 and 24 hpost injection.) mice were anaesthetized with an excess dose of Rompun/Ketalar mixture (Ketalar (ketamine): $10 \mathrm{mg} / \mathrm{mL}$, Pfizer AB, Stockholm, Sweden; Rompun (xylazine): $1 \mathrm{mg} / \mathrm{mL}$, Bayer AG, Leverkusen, Germany) and euthanized through cervical dislocation. Organs were collected, weighed and their activity content was measured using an automated $\gamma$-counter. Organ activity uptake was represented as percentage of injected dose per gram $(\% \mathrm{ID} / \mathrm{g})$.

\section{Results}

\subsection{Production of Constructs, Chelator Conjugation and Product Purification}

The mono- and bi-valent ABD-fused HER3-binding constructs were purified using HSA affinity chromatography, coupled to maleimide-DOTA and subjected to RP-HPLC for purification. The purity of the constructs, as determined by RP-HPLC, exceeded $96 \%$ for all five proteins (Figure S1).

\subsection{Characterization of the Conjugated Proteins}

Molecular mass determination with ESI-MS confirmed a concordance with the theoretical masses 12670.9 and 19601.6 Da for DOTA-conjugated monovalent and bivalent constructs, respectively (Table 1 and Figure S2). However, the constructs with N-terminally fused ABD (A3 and A33) exhibited a mass deviation of 131.2 Da, typically corresponding to non-processed N-terminal methionine. Furthermore, a smaller additional peak was observed, particularly for 3A3 and A33, which is likely due to a certain degree of unspecific coupling of the DOTA chelator.

The alpha-helical content, thermal stability and refolding of the DOTA-conjugated constructs were investigated with circular dichroism spectroscopy. The thermal denaturation curves for the constructs are shown in Figure S3A and the associated melting temperatures are presented in Table 1. The respective transitions in unfolding for the individual domains could not be resolved, indicating that the transitions are overlapping and the calculated melting temperatures thus represent an approximate average for the entire constructs. Following thermal denaturation, complete refolding of the constructs was evident from comparison of spectra obtained at $20^{\circ} \mathrm{C}$ before and after denaturation, with the exception of a small shift in helicity for $3 \mathrm{~A} 3$ and A33 (Figure S3B).

Table 1. Biophysical characteristics of different ABD-fused anti-HER3 affibody constructs. HSA: human serum albumin; $\mathrm{T}_{\mathrm{m}}$ : melting temperature; $\mathrm{K}_{\mathrm{D}}$ : equilibrium dissociation constant.

\begin{tabular}{ccccc}
\hline Construct & $\mathbf{M W}(\mathbf{D a})$ & $\mathbf{T}_{\mathbf{m}}\left({ }^{\circ} \mathbf{C}\right)$ & $\mathbf{K}_{\mathbf{D}}$, HER3 $(\mathbf{n M}$, Mean $\pm \mathbf{S D})$ & $\mathbf{K}_{\mathbf{D}}, \mathbf{H S A}(\mathbf{n M}$, Mean $\pm \mathbf{S D})$ \\
\hline 3A & $12,670.9$ & 61.3 & $0.3 \pm 0.03$ & $0.06 \pm 0.02$ \\
33A & $19,601.6$ & 66.1 & $0.6 \pm 0.03$ & $0.24 \pm 0.22$ \\
3A3 & $19,601.6$ & 62.4 & $1.1 \pm 0.1$ & $0.68 \pm 0.66$ \\
A33 & $19,732.8$ & 62.7 & $0.8 \pm 0.15$ & $0.35 \pm 0.24$ \\
A3 & $12,802.1$ & 61.8 & $0.6 \pm 0.15$ & $0.15 \pm 0.08$ \\
\hline
\end{tabular}

\subsection{Affinity Determination}

Kinetic data acquired from surface plasmon resonance (SPR) analysis is presented in Table 1 as the average of triplicates. All DOTA-conjugated constructs demonstrated high affinity to HER3 receptors in the low nanomolar range. $K_{D}$ values refer to the monovalent affinity for human HER3 according to a Langmuir 1:1 model. Representative sensorgrams with fitted curves for each construct are shown in 
Figure 2. Please note that the interactions were measured in a capture assay, comprising immobilized albumin on the surface followed by consecutive injections of the constructs and HER3. The determined affinities for HER3 are thus for the constructs simultaneously bound to albumin, which more closely represent the situation in vivo. To verify that the affinity for albumin was not dramatically affected by fusion to the affibody molecules, we performed an SPR analysis of the interaction of all constructs, respectively, to albumin. All constructs demonstrated subnanomolar affinity for albumin. The data is presented in Table 1, and the sensorgrams are shown in Figure S4.
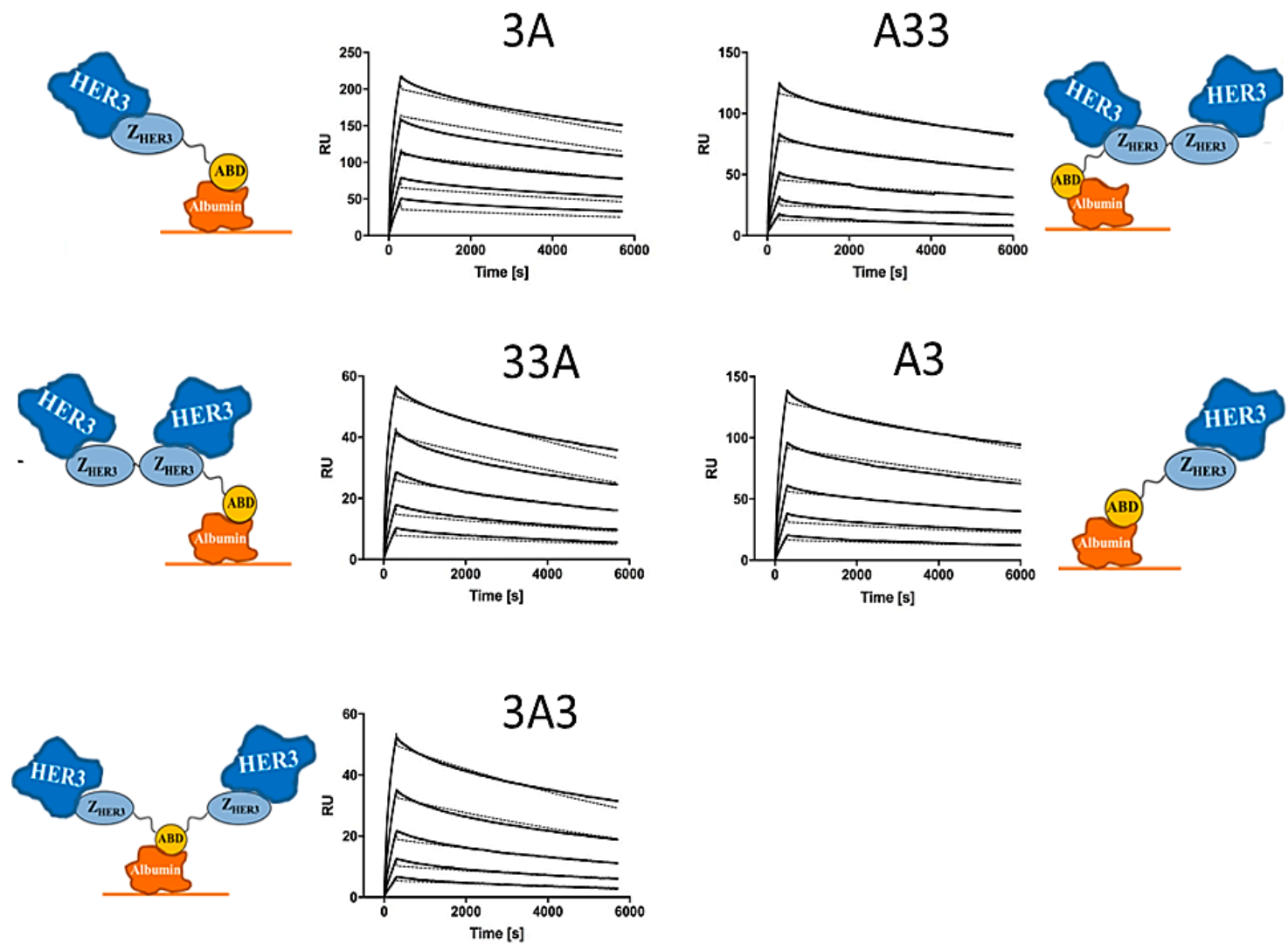

Figure 2. Representative experimental sensorgrams (solid) with fitted curves (dashed) from surface plasmon resonance (SPR) analysis for different ABD-fused anti-HER3 affibody constructs conjugated with a 1,4,7,10-tetraazacyclododecane-1,4,7,10-tetraacetic acid (DOTA) chelator at the C-terminus. Constructs were captured on immobilized HSA and subsequently subjected to five concentrations of human HER3 $(3.125,6.25,12.5,25$, and $50 \mathrm{nM})$. Monovalent affinities to HER3, based on a Langmuir 1:1 model, are presented in Table 1.

\subsection{Radiolabelling of Constructs with Indium-111 and Stability Test}

All DOTA-conjugated anti-HER3 constructs were successfully labelled with ${ }^{111}$ In, though with different labelling yields (Table 2). The radiochemical purity after size exclusion chromatography was over $95 \%$ for all conjugates. Challenge with a 500 -fold molar excess of EDTA did not show any measurable release of ${ }^{111}$ In when analysed using iTLC, as $>95 \%$ of the activity was associated to the protein (Table 2). 
Table 2. Radiolabelling yield, radiochemical purity after purification using a NAP-5 size exclusion column, and stability on ethylenediaminetetraacetic acid (EDTA) challenge of different ${ }^{111}$ In-labelled ABD-fused anti-HER3 affibody molecules.

\begin{tabular}{cccc}
\hline Construct & $\begin{array}{c}\text { Radiolabelling } \\
\text { Yield (\%) }\end{array}$ & $\begin{array}{c}\text { Radiochemical Purity } \\
\text { of Conjugates (\%) }\end{array}$ & $\begin{array}{c}\text { Protein Associated Activity after 1 h of Incubation } \\
\text { with a 500-Fold Molar Excess of EDTA (\%) }\end{array}$ \\
\hline 3A & $89 \pm 8$ & $99 \pm 1$ & $99.6 \pm 0.3$ \\
33A & $85.1 \pm 0.1$ & $98.6 \pm 0.8$ & $99.4 \pm 0.1$ \\
3A3 & $51 \pm 12$ & $98 \pm 1$ & $98 \pm 1$ \\
A33 & $28 \pm 6$ & $97 \pm 2$ & $96 \pm 1$ \\
A3 & $45 \pm 4$ & $97 \pm 2$ & $96 \pm 1$ \\
\hline
\end{tabular}

\subsection{Inhibition of Phosphorylation}

Human phospho-HER3 ELISA was performed to investigate the influence of the affibody constructs on ligand-induced phosphorylation of HER3 in BxPC-3 and DU-145 cells (Figure 3). In both cell lines, stimulation of HER3 with the natural ligand heregulin showed a significant increase in signalling compared to the negative control, reflecting increased levels of phosphorylated HER3. Cell treatment with the affibody constructs prior to stimulation with heregulin resulted in a significantly lower level of phosphorylated HER3 than in the positive, heregulin-treated control. For BxPC-3 cells, the signalling from the groups treated with affibody constructs was below the level of the negative control. For DU-145 cells with lower HER3 expression level, the signal of the affibody-treated groups matched the signalling of the unstimulated negative control.

A

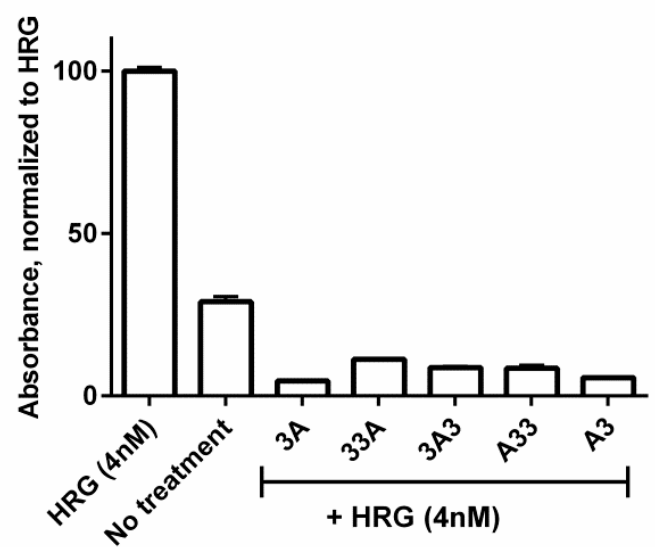

B

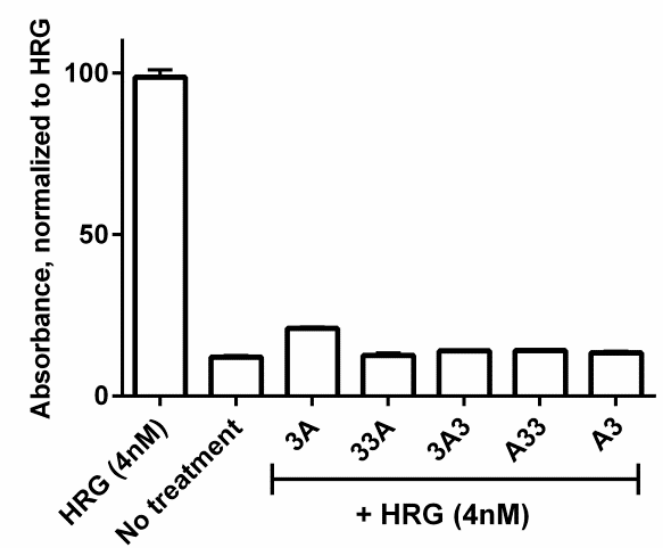

Figure 3. Inhibition efficacy. The relative levels of phosphorylated HER3 for BxPC-3 (A) and DU-145 (B) cells treated with $4 \mathrm{nM}$ heregulin. Signal was measured using Phospho-HER3 ELISA assay and normalized to the signal of the positive control. Cells were treated either with $4 \mathrm{nM}$ of heregulin or $200 \mathrm{nM}$ of affibody construct, followed by stimulation with $4 \mathrm{nM}$ heregulin. For negative control, cells were left untreated. Data are presented as an average $\pm \operatorname{SD}(n=3)$.

\subsection{In Vitro Specificity}

The binding of all radiolabelled constructs to HER3-expressing cells was significantly reduced $(p<0.05)$ when cells were preincubated with an excess-fold of the non-labelled anti-HER3 affibody

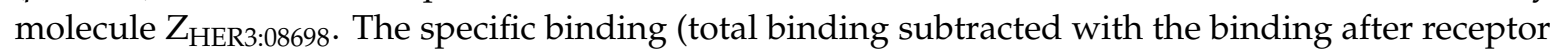
saturation) of different constructs to HER3-expressing cells is presented in Figure 4. 
BxPC-3

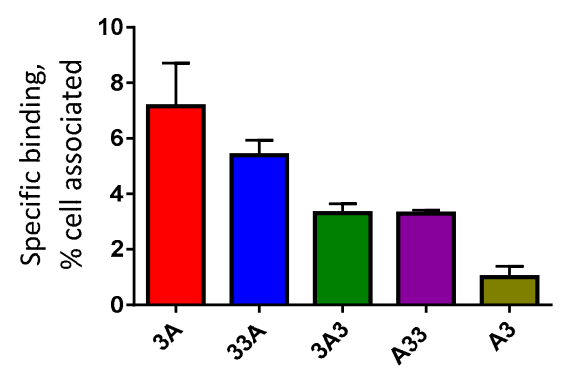

LS174t

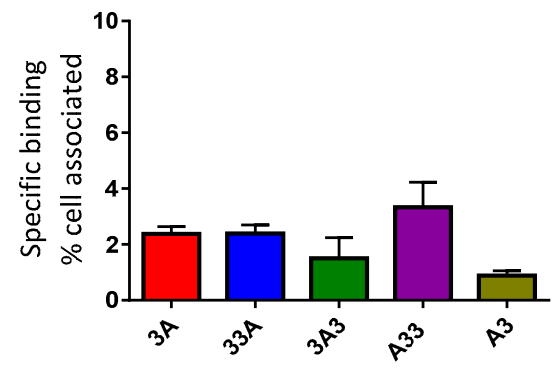

DU-145

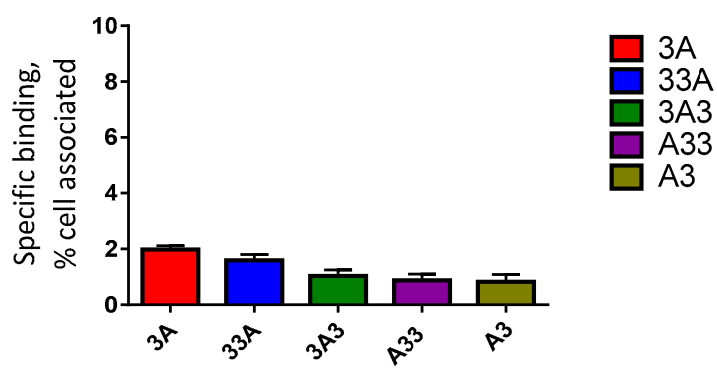

MCF-7

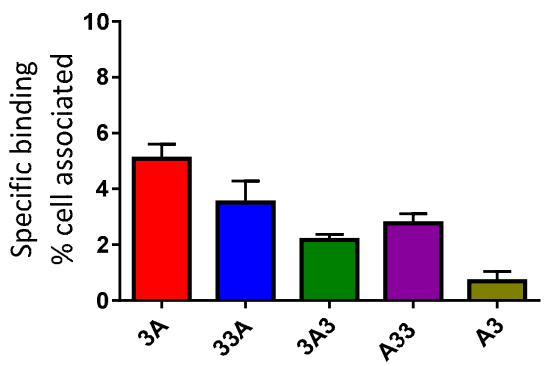

Figure 4. Specific binding (total binding subtracted with the binding after receptor saturation) of different ${ }^{111}$ In-labelled ABD-fused anti-HER3 affibody molecules to HER3-expressing cells (BxPC-3, DU-145, LS174T, and MCF-7) in vitro. Data are presented as an average \pm SD $(n=3)$ for the percentage of cell-bound radioactivity from totally added radioactivity.

\subsection{Cellular Processing and Internalization}

The estimated HER3 expression was $(15 \pm 2) \times 10^{3}$ receptors/cell for MCF-7 cells (high) and $(2.8 \pm 3) \times 10^{3}$ receptors/cell for DU-145 cells (low). Reported HER3 expression was (12 \pm 2$)$ $\times 10^{3}$ receptors/cell for BxPC-3 cells (high) and $(8.0 \pm 0.6) \times 10^{3}$ receptors/cell for LS174T cells (moderate) [21].

Results from the assessment of cellular processing and internalization of the radiolabelled anti-HER3 constructs on different cell lines are shown in Figure 5 and Figure S5. In general, there was a similarity in the pattern of processing in all four tested cell lines. All constructs showed a moderate but continuous growth of cell-bound activity up to $24 \mathrm{~h}$ of incubation. Among all studied constructs, 3A3 demonstrated the fastest increase of cell-associated activity in all cell lines. The internalization of all conjugates also increased during the whole experiment, although at different rates. Among all studied constructs 3A3 demonstrated the highest rate of internalization in all studied HER3-expressing cell lines. The rate of internalization of 33A was comparable to that of 3A3 in the DU-145, LS174T, and MCF-7 cells but not in the BxPC-3 cells. A common finding from all studied cell lines was the low total cellular uptake of A3. The internalization rate of A3 was also the lowest compared to other studied constructs. 
A.

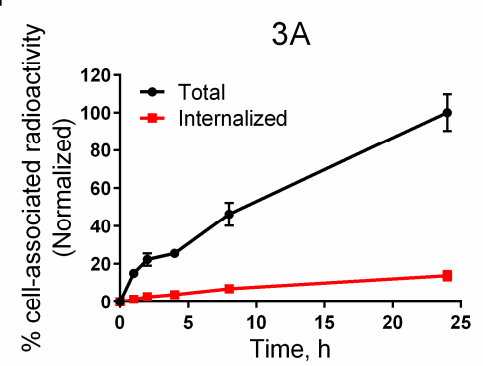

$33 \mathrm{~A}$

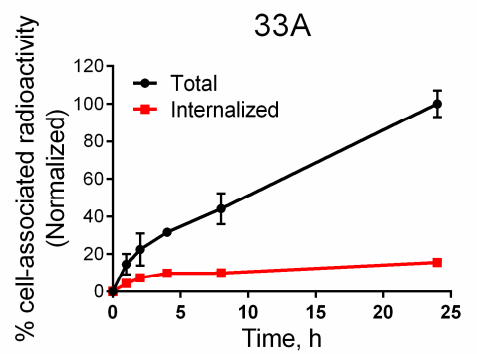

3A3

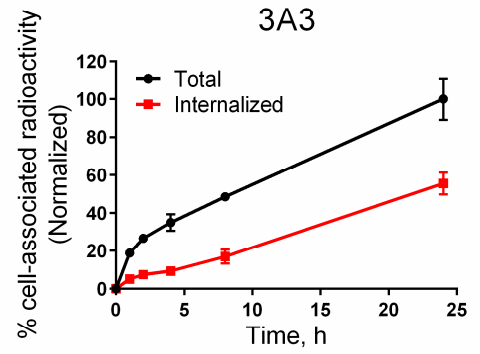

A33

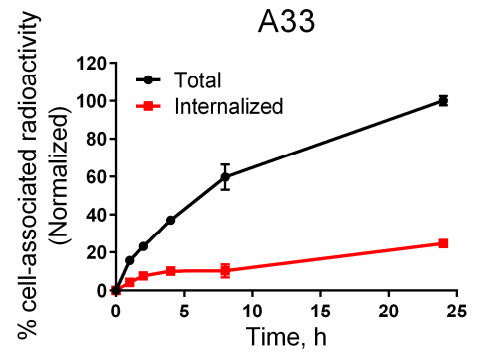

A3

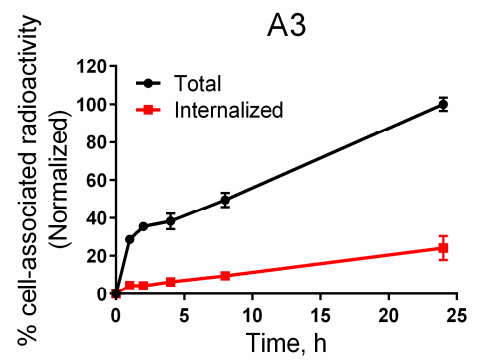

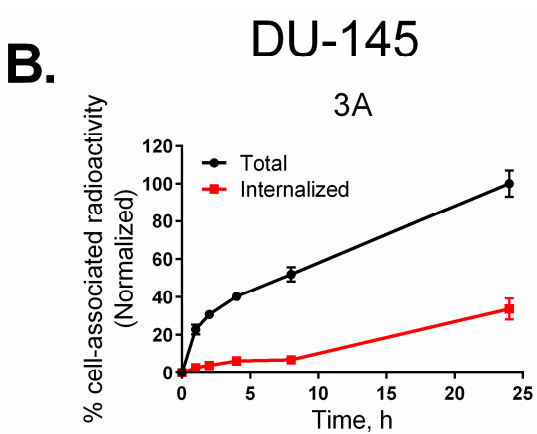

$33 \mathrm{~A}$

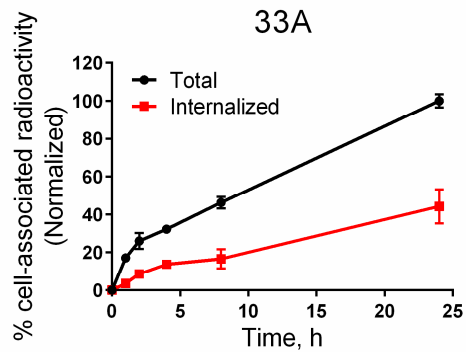

$3 A 3$

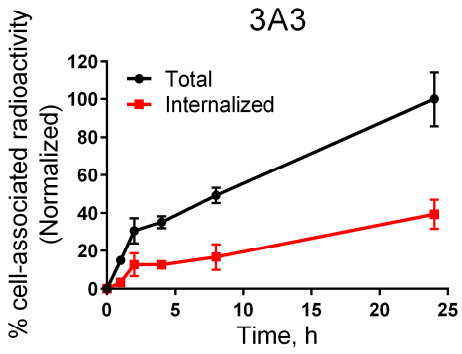

A33

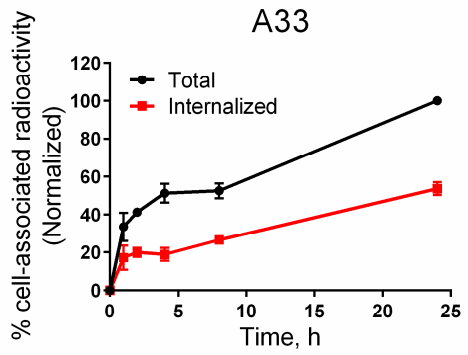

A3

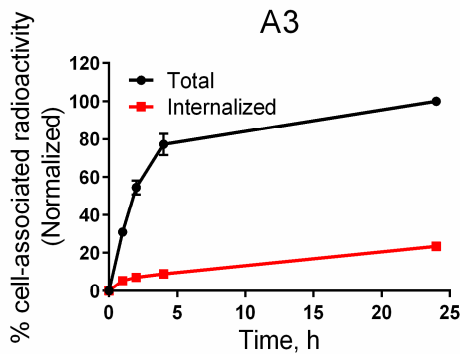

Figure 5. Cellular processing of different ${ }^{111}$ In-labelled ABD-fused anti-HER3 affibody molecules by HER3-expressing BxPC-3 (A) and DU-145 (B) cell lines with up to $24 \mathrm{~h}$ of continuous incubation. Data were normalized to the maximum uptake in each cell line. Data is presented as an average $\pm \operatorname{SD}(n=3)$. 


\subsection{In Vivo Studies}

Data concerning tumour targeting and biodistribution of labelled constructs 1,6 , and $24 \mathrm{~h}$ p.i. in BxPC-3 xenografted BALB/c-nu/nu mice is represented in Table 3.

Table 3. Biodistribution of ${ }^{111}$ In-labelled ABD-fused anti-HER3 affibody molecules in female BALB/c-nu/nu mice with BxPC-3 xenografts 1, 6, and $24 \mathrm{~h}$ after intravenous injection. The measured radioactivity of different organs is expressed as \% of injected dose per gram tissue (\%ID/g), and presented as an average value from four animals \pm SD. GI tract: gastrointestinal tract.

\begin{tabular}{|c|c|c|c|c|c|}
\hline Organ & $3 \mathrm{~A}$ & $33 \mathrm{~A}$ & $3 A 3$ & A33 & A3 \\
\hline \multicolumn{6}{|l|}{$1 \mathrm{~h}$} \\
\hline Blood & $33 \pm 3^{c, d}$ & $25 \pm 2$ & $24 \pm 1$ & $20.2 \pm 0.9$ & $21 \pm 1$ \\
\hline Salivary gland & $3.6 \pm 1.0$ & $2.8 \pm 0.4$ & $2.6 \pm 0.6$ & $2.4 \pm 0.5$ & $2.7 \pm 0.5$ \\
\hline Lung & $12 \pm 2$ & $10 \pm 2^{f}$ & $8 \pm 1$ & $8 \pm 2$ & $8.2 \pm 0.8$ \\
\hline Liver & $7 \pm 2$ & $13 \pm 1^{g}$ & $7 \pm 1$ & $9 \pm 2$ & $5.8 \pm 0.6$ \\
\hline Spleen & $6 \pm 1$ & $8 \pm 2$ & $5.0 \pm 0.6$ & $5.9 \pm 0.4^{\mathrm{j}}$ & $4.0 \pm 0.2$ \\
\hline Stomach & $2.0 \pm 0.3$ & $1.9 \pm 0.5$ & $1.5 \pm 0.3$ & $1.5 \pm 0.4$ & $1.6 \pm 0.2$ \\
\hline Small intestine & $5 \pm 1$ & $5.5 \pm 0.4$ & $3.6 \pm 0.3$ & $3.4 \pm 0.6$ & $3.6 \pm 0.8$ \\
\hline Kidney & $10 \pm 2^{b, c, d}$ & $11 \pm 1^{e, f, g}$ & $22 \pm 2^{h}$ & $41 \pm 3$ & $33 \pm 2$ \\
\hline Tumour & $4.1 \pm 0.5$ & $4.3 \pm 0.4$ & $3.2 \pm 0.7$ & $4 \pm 1$ & $4 \pm 2$ \\
\hline Muscle & $1.0 \pm 0.1$ & $0.9 \pm 0.2$ & $0.9 \pm 0.1$ & $0.7 \pm 0.1$ & $0.7 \pm 0.1$ \\
\hline Bone & $2.4 \pm 0.3$ & $2.4 \pm 0.4$ & $1.9 \pm 0.7$ & $1.7 \pm 0.5$ & $2.0 \pm 0.9$ \\
\hline GI tract * & $4 \pm 1$ & $4.7 \pm 0.7^{k}$ & $3.1 \pm 0.7$ & $2.7 \pm 0.3$ & $2.9 \pm 0.5$ \\
\hline Carcass * & $32 \pm 6$ & $30 \pm 2^{f, k}$ & $27 \pm 2$ & $21 \pm 2$ & $25.2 \pm 0.7$ \\
\hline \multicolumn{6}{|l|}{$6 \mathrm{~h}$} \\
\hline Blood & $19 \pm 2^{a, c, k}$ & $9.5 \pm 0.8^{k}$ & $14 \pm 2^{k}$ & $9 \pm 1^{k}$ & $16 \pm 2$ \\
\hline Salivary gland & $4.3 \pm 0.4^{c}$ & $3.35 \pm 0.08^{f}$ & $3.2 \pm 0.5^{h}$ & $2.1 \pm 0.2$ & $3.8 \pm 0.7$ \\
\hline Lung & $9.0 \pm 0.6^{a, c}$ & $6.8 \pm 1.0^{f}$ & $6 \pm 1$ & $4.3 \pm 0.6^{j}$ & $8.4 \pm 0.9$ \\
\hline Liver & $6.2 \pm 0.3^{a}$ & $19 \pm 1.5^{e, f, g, k}$ & $6.6 \pm 0.6$ & $9.1 \pm 0.6$ & $5.6 \pm 0.3$ \\
\hline Spleen & $4.4 \pm 0.8^{a}$ & $14.0 \pm 0.3^{e, f, g, k}$ & $5.7 \pm 0.7$ & $8 \pm 2$ & $5 \pm 1$ \\
\hline Stomach & $2.5 \pm 0.4^{k}$ & $2.5 \pm 0.2^{f}$ & $1.6 \pm 0.3$ & $1.5 \pm 0.2^{j}$ & $2.24 \pm 0.09$ \\
\hline Small intestine & $4.3 \pm 0.7$ & $9 \pm 3$ & $3.5 \pm 0.9$ & $4 \pm 1$ & $4.2 \pm 0.7$ \\
\hline Kidney & $9 \pm 1^{a, b, c, d}$ & $12.0 \pm 0.6^{f, g, k}$ & $21 \pm 2^{h}$ & $41 \pm 4$ & $44 \pm 8$ \\
\hline Tumour & $8 \pm 2^{a}$ & $13 \pm 2^{e, f}$ & $7 \pm 1$ & $7 \pm 1$ & $8 \pm 1$ \\
\hline Muscle & $1.6 \pm 0.2^{c, k}$ & $1.08 \pm 0.09$ & $1.0 \pm 0.2$ & $0.72 \pm 0.07^{k}$ & $1.3 \pm 0.1$ \\
\hline Bone & $2.0 \pm 0.2$ & $4 \pm 1$ & $1.8 \pm 0.4$ & $1.68 \pm 0.07$ & $2.4 \pm 0.5$ \\
\hline GI tract* & $5.8 \pm 0.7^{a}$ & $8.7 \pm 0.8^{f, g}$ & $4 \pm 1$ & $3.97 \pm 0.07^{k}$ & $4.1 \pm 0.2$ \\
\hline Carcass * & $40 \pm 3^{c}$ & $36 \pm 3^{f}$ & $32 \pm 2^{h}$ & $20.8 \pm 0.1^{j, k}$ & $33.9 \pm 0.3$ \\
\hline \multicolumn{6}{|l|}{$24 \mathrm{~h}$} \\
\hline Blood & $10 \pm 2^{a, c, l, m}$ & $1.0 \pm 0.2^{e, g, l, m}$ & $6.7 \pm 0.8^{h, l, m}$ & $2.0 \pm 0.3^{j, l, m}$ & $6.3 \pm 0.6^{l, m}$ \\
\hline Salivary gland & $4.4 \pm 0.7$ & $2.5 \pm 0.5$ & $3.3 \pm 0.2^{h}$ & $2.1 \pm 0.3^{j}$ & $3.2 \pm 0.2$ \\
\hline Lung & $5.8 \pm 0.7^{c, l, m}$ & $2.7 \pm 0.8^{l, m}$ & $4.5 \pm 0.8$ & $1.9 \pm 0.3^{l, m}$ & $3.6 \pm 0.7^{l, m}$ \\
\hline Liver & $5.9 \pm 0.6^{a, c}$ & $19 \pm 2^{e f f, g}$ & $8 \pm 1$ & $10.1 \pm 0.3^{j}$ & $5.3 \pm 0.6$ \\
\hline Spleen & $5.0 \pm 0.8$ & $15 \pm 5$ & $6.6 \pm 0.8$ & $6.7 \pm 0.8$ & $3.4 \pm 0.7$ \\
\hline Stomach & $2.3 \pm 0.3^{c, m}$ & $1.7 \pm 0.7$ & $1.7 \pm 0.2$ & $1.2 \pm 0.1$ & $1.7 \pm 0.3$ \\
\hline Small intestine & $6 \pm 1$ & $7 \pm 3$ & $4.4 \pm 0.3$ & $3.3 \pm 0.2$ & $4.1 \pm 0.6$ \\
\hline Kidney & $7.5 \pm 0.7^{b, c, d}$ & $9 \pm 2^{f, g}$ & $19 \pm 1 h, i$ & $32.7 \pm 0.6^{l, m}$ & $31 \pm 3$ \\
\hline Tumour & $9 \pm 2^{m}$ & $12 \pm 2^{f, m}$ & $9 \pm 1^{h, i}$ & $6.5 \pm 0.9$ & $5.9 \pm 0.4$ \\
\hline Muscle & $1.2 \pm 0.2^{l}$ & $0.6 \pm 0.1$ & $1.0 \pm 0.1$ & $0.6 \pm 0.1$ & $0.9 \pm 0.2$ \\
\hline Bone & $2.3 \pm 0.4$ & $3 \pm 1$ & $1.7 \pm 0.6$ & $1.7 \pm 0.3^{l}$ & $1.5 \pm 0.3$ \\
\hline GI tract * & $5.8 \pm 0.8^{c, m}$ & $6 \pm 1$ & $4.1 \pm 0.4$ & $3.2 \pm 0.3^{m}$ & $5.2 \pm 0.4$ \\
\hline Carcass * & $36 \pm 3^{c}$ & $27 \pm 3^{l}$ & $29 \pm 3$ & $16 \pm 1^{l}$ & $25 \pm 2$ \\
\hline
\end{tabular}

* Data for gastro-intestinal tract with content and carcass are presented as percentage of injected radioactivity per whole sample. Data were assessed by one-way ANOVA with Bonferronni correction for multiple comparisons in order to determine significant differences between groups $(p<0.05)$. ${ }^{a}-3 \mathrm{~A}$ vs. $33 \mathrm{~A}$ at this time point; ${ }^{b}-3 \mathrm{~A}$ vs. $3 \mathrm{~A} 3$ at this time point; ${ }^{c}-3 \mathrm{~A}$ vs. $\mathrm{A} 33$ at this time point; ${ }^{d}-3 \mathrm{~A}$ vs. $\mathrm{A} 3$ at this time point; ${ }^{e}-33 \mathrm{~A}$ vs. $3 \mathrm{~A} 3$ at this time point; $f-33 \mathrm{~A}$ vs. A33 at this time point; ${ }^{g}-33 \mathrm{~A}$ vs. A3 at this time point; ${ }^{h}-3 \mathrm{~A} 3 \mathrm{vs}$. A33 at this time point; ${ }^{i}-3 \mathrm{~A} 3 \mathrm{vs}$. A3 at this time point; ${ }^{j}-\mathrm{A} 33$ vs. A3 at this time point; ${ }^{k}-1$ h p.i. vs. $6 \mathrm{~h}$ p.i. for this conjugate; ${ }^{l}-6$ vs. $24 \mathrm{~h}$ p.i. for this conjugate; $^{m}-1$ vs. 24 h p.i. for this conjugate.

Overall, the study demonstrated a strong influence of composition of ABD-fused HER3-targeting agents on overall biodistribution. Most obvious was the influence on activity uptake in blood, 
tumours, excretory organs (kidney and liver), and organs with endogenous expression of murine ErbB3 (particularly the liver). It is apparent that ABD fusion resulted in prolonged retention in the blood for all constructs, however at different levels. All studied constructs demonstrated comparable blood-associated activity $1 \mathrm{~h}$ p.i. except for the 3A construct, which had significantly higher activity. The dimeric constructs, where the ABD scaffold was located on either of the termini (33A and A33), showed faster clearance from the blood between 1 and $24 \mathrm{~h}$ p.i. The blood-associated activity was reduced 23-fold for 33A and 10-fold for A33, but only ca. 3-3.5-fold for the other studied constructs. Regardless, 3A still demonstrated significantly higher retention of activity in the blood up to $24 \mathrm{~h}$ p.i. compared to the other constructs. A similar effect was also observed for the monomeric construct A3 with the ABD relocated to the $\mathrm{N}$-terminus of the anti-HER3 affibody molecule.

The rapid washout of 33A from the blood was accompanied with high activity accumulation in the tumour and liver. No similar effect was observed for construct A33. Despite its longer retention in the circulation compared to $33 \mathrm{~A}$, the monovalent $3 \mathrm{~A}$ construct had significantly lower accumulation in the tumour $6 \mathrm{~h}$ p.i. However, there was no significant difference in the tumour uptake between $3 \mathrm{~A}$ and $33 \mathrm{~A}$ by the end of the experiment. Moreover, $3 \mathrm{~A}$ demonstrated significantly lower activity accumulation in the liver compared to 33A throughout the experiment. On the other hand, the tumour accumulated activity of both A33 and A3 was the lowest $(p<0.05)$ among all studied constructs 24 h p.i.

Changing the position of $\mathrm{ABD}$ from C-terminus in 3A and 33A to N-terminus in A3 and A33 resulted in significantly lower uptake in the kidneys at all studied time points. Throughout the study the previously investigated format $3 \mathrm{~A} 3$ demonstrated moderate uptake in tumour and kidneys and somewhat lower liver uptake compared to the other constructs.

\section{Discussion}

HER3 overexpression in malignant tumours has been associated with resistance to targeted therapy and poor overall survival. MAbs directed against HER3 (e.g., seribantumab) have been investigated in the clinics in combination with different therapies for treatment of various types of cancers and demonstrated promising results [34]. Affibody molecules represent a non-immunoglobulin-based alternative to mAbs. Plasma half-life extension through genetic fusion of affibody molecules to ABD significantly increases bioavailability of affibody-based targeting agents [23]. It is worth mentioning that the size of the affibody-ABD fused proteins bound to albumin is ca. $80 \mathrm{kDa}$, approximately only half the size of full-length mAbs (ca. $150 \mathrm{kDa}$ ). A small size would mean increased tumour tissue penetration and homogeneity of distribution compared to $\mathrm{mAbs}$ [35]. In addition, binding to albumin enables maintaining a sufficiently high concentration of the administered drug in the blood and extracellular space, which could increase potency and improve patient compliance by allowing fewer administrations. We and others have demonstrated the feasibility of HER3 targeting using anti-HER3 affibody molecules [22,36] and bivalent HER3 targeting constructs, with two HER3-specific affibody molecules flanking the $\mathrm{ABD}$ demonstrating potent anti-proliferative effects both in vitro and in vivo $[27,28]$. In the present study, we have designed and explored four novel formats of anti-HER3 affibody molecules fused to ABD (3A, 33A, A3, A33) and the previously investigated 3A3 with the aim to identify an optimal construct design.

All new constructs demonstrated high binding affinity as well as specificity to HER3 receptors. Retaining the capacity to bind HER3 with high affinity is essential as many cancers have low to moderate levels of HER3 expression. Binding of all newly designed affibody constructs was found to inhibit the heregulin-induced phosphorylation in HER3-expressing BxPC-3 and DU-145 cell lines with similar efficiency. Surprisingly, the signal in BxPC-3 negative control was higher in comparison with the DU-145 negative control (Figure 3A). This might be due to the autocrine properties of BxPC-3 cells secreting heregulin as well as other growth factors $[37,38]$. The ability to self-induce phosphorylation is thought to be important for HER3-associated resistance mechanisms to anti-HER treatments. We have previously observed that absolute inhibition of cell proliferation using a construct similar to 
3A3 in vitro was not possible due to this autocrine effect [27]. Nevertheless, inhibition of growth of HER3-expressing cancer cells was efficient and a pilot in vivo therapy study confirmed that it was possible to delay growth of autocrine BxPC-3 xenografts using this construct [27].

Site-specific labelling of affibody molecules with indium-111 via DOTA facilitated comparative evaluation of the different constructs both in vitro and in vivo. Binding of all constructs to HER3 receptors was preserved after radiolabelling as shown in Figure 4.

Cell lines with low to high HER3 expression levels were included in this study. It was demonstrated in clinical studies that not only HER3 expression but also levels of heregulin and HER2 expression influence therapeutic outcome for anti-HER3 treatment [39]. Results from the cellular processing experiments revealed that the format of ABD-fused anti-HER3 affibody molecules had an apparent influence on the processing and internalization of targeting agents after binding to HER3-expressing cells Figure 5 and Figure S5. However, no common pattern of internalization was observed, and different constructs behaved differently in the studied panel of cell lines. This is in line with previous reports on the monomeric anti-HER3 affibody $Z_{\text {HER3:08699, which was highly internalized }}$ by the cells with high (BT474, $(25 \pm 2) \times 10^{3}$ receptors/cell, BxPC-3, $(12 \pm 2) \times 10^{3}$ receptors/cell) HER3 expression but not by the cells with moderate HER3-expression (LS174T, $(8.0 \pm 0.6) \times 10^{3}$ receptors/cell) [21]. One speculation is that the observed disparity in processing and internalization of HER3-binders in different cell lines might partly be due to differences in levels of HER3 production and expression [27]. Another contributing factor could be the co-expression of the HER family receptors EGFR (epidermal growth factor receptor) and HER2 and the formation of different heterodimers with HER3, which may be involved in altering the internalization patterns of different conjugates. For example, Barta and co-workers observed earlier that binding of affibody molecules targeting HER2 in DU-145 and SKOV-3 cells were influenced by the level of co-expression of EGFR in these cell lines [40].

Furthermore, results from the cellular processing have also shown that the HER3-targeting constructs were processed differently by the same cell line. As the level of target expression within an individual cell line is equal, differences in processing of the studied constructs can probably be attributed to a varying ability to trigger HER3 internalization. The bivalent 3A3 may for example induce HER3 internalization in a way similar to that observed for HER3 targeting mAbs, thus resulting in higher internalization rate of this format compared to other constructs [41]. Although it is beyond the scope of this study, increased internalization of some formats may render these constructs promising candidates for payload delivery of cytotoxic agents and small drug molecules to tumour cells.

Due to the extremely high concentration of albumin in blood (around $40 \mathrm{mg} / \mathrm{mL}$ ), only a moderate affinity for serum is needed for extending the in vivo half-life [42]. All tested conjugates demonstrated high affinity to albumin (from subnanomolar to low picomolar). As expected, the circulatory half-life was prolonged for all conjugates by the inclusion of ABD (Table 3). Activity concentration in blood $1 \mathrm{~h}$ p.i. was 20-30-fold higher for the studied constructs than for anti-HER3 monomer [22]. The magnitude of this enhancement was in accordance with the effect observed earlier for both monomeric and dimeric anti-HER2 and anti-HER3 affibody molecules, fused either on the $\mathrm{N}$ - or C-termini of ABD $[27,43,44]$. Surprisingly, the effect on circulatory half-life of the bivalent formats with terminal $\mathrm{ABD}, 33 \mathrm{~A}$ and $\mathrm{A} 33$ was not as prominent compared to the other studied constructs. The elimination of $33 \mathrm{~A}$ and A33 from blood was faster compared to that of $3 \mathrm{~A}, 3 \mathrm{~A} 3$, and A3. This unexpected behaviour might be associated with compromised binding to albumin as a result of structure-related steric hindrance caused by two consecutively coupled HER3 targeting monomers. Decreased binding to albumin might render freely circulating 33A and A33 more efficiently sequestered from the blood by murine ErbB3-expressing tissues. The significantly higher uptake of labelled 33A and A33 in the liver and spleen supports this hypothesis.

The comparative biodistribution study showed the capacity of ABD-fused proteins to accumulate in HER3-expressing tumours. Interestingly, the fusion protein 33A provided higher tumour uptake values compared to other conjugates at as early as $6 \mathrm{~h}$ p.i., likely due to elevated fraction of freely 
circulating 33A (i.e., not bound to albumin) that also leads to more rapid blood clearance. On the other hand, 3A and 3A3 conjugates had a longer residence time in blood than 33A and had better bioavailability $24 \mathrm{~h}$ p.i. However, this was not the case for A33 where rapid washout from the circulation was not accompanied by increased accumulation in the tumour. In fact, more A33 was directed towards the kidneys and excreted. The A3 format also demonstrated elevated renal excretion and low tumour accumulation. The observed low accumulation of A3 in the tumour is not in good agreement with the measured high binding affinity to recombinant HER3 (subnanomolar) in the biosensor assay (Table 1). However, A3 also had the lowest binding to HER3-expressing cells in vitro (Figure 4). The discrepancy between the affinity using immobilized recombinant receptors and both in vitro and in vivo assays suggests that the ligand-receptor interaction is more complicated in the latter case, and that sorting of targeting agents might not be addressed adequately using a single criterion. Together, results from the comparative biodistribution study indicate that placing ABD at the N-terminus of HER3-targeting affibody molecules is associated with suboptimal in vivo targeting properties. Moreover, the enhanced plasma half-life of our newly designed 3A3 resulted in reduced renal uptake as well as improved targeting of HER3-expressing BxPC-3 xenografts compared to the previously reported $3 \mathrm{~A} 3$ variant by Bass et al. [27].

It is especially interesting to compare the $3 \mathrm{~A} 3$ variant used in this study with the one previously reported by Bass et al. [27]. Despite the fact that such a comparison is not the main aim of this study and that the two variants were not compared head-to-head, we still believe that comparing these two is useful for showing the importance of the structure-properties relationship in drug design. The newly designed 3A3 demonstrated 10-fold higher activity concentration in blood and ca. 1.5-fold lower activity in liver and kidneys $24 \mathrm{~h}$ p.i. compared to the previously reported $3 \mathrm{~A} 3$ by Bass et al. $((6.7 \pm 0.8)$ vs. $(0.6 \pm 0.2) \% \mathrm{ID} / \mathrm{g}$ in blood, $(8 \pm 1)$ vs. $(15 \pm 1) \% \mathrm{ID} / \mathrm{g}$ in liver, and $(19 \pm 1)$ vs. $(30 \pm 4)$ $\% \mathrm{ID} / \mathrm{g}$ in kidneys). Such significant differences in blood retention between the two constructs cannot solely be explained by batch-to-batch variability of animals. As mentioned above, the newly designed $3 \mathrm{~A} 3$ used in the current study comprises a shorter $\mathrm{G}_{3} \mathrm{~S}$ linker between binding moieties instead of the previously used $\left(\mathrm{S}_{4} \mathrm{G}\right)_{4}$ linker. It is likely that potential constraints on the albumin-binding activity of $3 \mathrm{~A} 3$ were alleviated with the shorter linker, thus enabling stronger binding to serum albumin. Another aspect is the observed difference in tumour uptake between the $3 \mathrm{~A} 3$ variant used in this study and the previously reported variant $((9 \pm 1)$ vs. $(5.3 \pm 0.7) \% \mathrm{ID} / \mathrm{g}, 24 \mathrm{~h}$ p.i., respectively). One may speculate that such difference may be partially explained by differences in blood retention and overall bioavailability between the two variants. We also cannot exclude that tumour batch-to-batch variability may have contributed to such observed differences, and in future a head-to-head comparison of the two variants is thus warranted in order to draw solid conclusions.

In conclusion, the present study has increased the understanding of the connection between molecular structures and properties for development of smaller HER3-targeting affibody molecules with prolonged half-life. The formats with ABD located on the C-terminus of affibody binding domains ( $3 \mathrm{~A}$ and $33 \mathrm{~A}$ ) as well as the redesigned $3 \mathrm{~A} 3$ format provided the best tumour-targeting properties in vivo. Further evaluation of these promising targeting agents is therefore justified.

Supplementary Materials: The following are available online at http:/ / www.mdpi.com/2073-4409/7/10/164/s1, Figure S1: Purity determination. Figure S2: Mass determination. Figure S3: Analysis of thermal stability and refolding capacity of DOTA-conjugated constructs. Figure S4: Analysis of binding affinity to HSA. Figure S5: Cellular processing of different ${ }^{111} \mathrm{In}$-labelled ABD-fused anti-HER3 affibody molecules by LS174T and MCF-7 cells.

Author Contributions: M.A. and C.D.L. contributed equally to this study. M.A., C.D.L., S.S.R., S.S., V.T., J.L. and A.O., conceived and designed experiments. M.A., C.D.L., S.S.R., A.V., C.A., V.T., J.L. and A.O. performed the experiments and analysed the data. M.A., C.D.L., S.S.R., J.L. and A.O. wrote the paper.

Funding: This work was supported by the Swedish Cancer Society (grants CAN2016-463 (S.S.), CAN2014-474, CAN 2017/425 (A.O.) and CAN2015/350 (V.T.)), the Swedish Research Council (grants 621-2012-5236 (S.S.), 2015-02509 (A.O.) and 2015-02353 (V.T.)), the Wallenberg Center for Protein Technology (S.S., J.L.), an ESCAPE Cancer grant from the Swedish Agency for Innovation VINNOVA (2016-04060, A.O.), and the Swedish Society for Medical Research (M.A.). 
Conflicts of Interest: S.S., V.T., and A.O. own shares in Affibody AB. M.A., S.S.R., C.D.L., A.V., and C.A. declare no conflict of interest.

\section{References}

1. Hanahan, D.; Weinberg, R.A. Hallmarks of cancer: The next generation. Cell 2011, 144, 646-674. [CrossRef] [PubMed]

2. Lemmon, M.A.; Schlessinger, J. Cell signaling by receptor tyrosine kinases. Cell 2010, 141, 1117-1134. [CrossRef] [PubMed]

3. Ecker, D.M.; Jones, S.D.; Levine, H.L. The therapeutic monoclonal antibody market. MAbs 2015, 7, 9-14. [CrossRef] [PubMed]

4. Lambert, J.M.; Berkenblit, A. Antibody-Drug Conjugates for Cancer Treatment. Annu. Rev. Med. 2018, 69, 191-207. [CrossRef] [PubMed]

5. Karachaliou, N.; Lazzari, C.; Verlicchi, A.; Sosa, A.E.; Rosell, R. HER3 as a Therapeutic Target in Cancer. BioDrugs 2017, 31, 63-73. [CrossRef] [PubMed]

6. Ma, J.; Lyu, H.; Huang, J.; Liu, B. Targeting of erbB3 receptor to overcome resistance in cancer treatment. Mol. Cancer 2014, 13, 105. [CrossRef] [PubMed]

7. Ruigrok, V.J.; Levisson, M.; Eppink, M.H.; Smidt, H.; van der Oost, J. Alternative affinity tools: More attractive than antibodies? Biochem. J. 2011, 436, 1-13. [CrossRef] [PubMed]

8. Nygren, P.A.; Skerra, A. Binding proteins from alternative scaffolds. J. Immunol. Methods 2004, 290, 3-28. [CrossRef] [PubMed]

9. Feldwisch, J.; Tolmachev, V. Engineering of affibody molecules for therapy and diagnostics. Methods Mol. Biol. 2012, 899, 103-126. [CrossRef] [PubMed]

10. Andersen, J.T.; Pehrson, R.; Tolmachev, V.; Daba, M.B.; Abrahmsén, L.; Ekblad, C. Extending half-life by indirect targeting of the neonatal $\mathrm{Fc}_{\mathrm{C}}$ receptor $(\mathrm{FcRn})$ using a minimal albumin binding domain. J. Biol. Chem. 2011, 286, 5234-5241. [CrossRef] [PubMed]

11. Frejd, F.Y.; Kim, K.T. Affibody molecules as engineered protein drugs. Exp. Mol. Med. 2017, 49, e306. [CrossRef] [PubMed]

12. Simeon, R.; Chen, Z. In vitro-engineered non-antibody protein therapeutics. Protein Cell 2018, 9, 3-14. [CrossRef] [PubMed]

13. Nord, K.; Gunneriusson, E.; Ringdahl, J.; Ståhl, S.; Uhlén, M.; Nygren, P.A. Binding proteins selected from combinatorial libraries of an alpha-helical bacterial receptor domain. Nat. Biotechnol. 1997, 15, 772-777. [CrossRef] [PubMed]

14. Ståhl, S.; Gräslund, T.; Eriksson Karlström, A.; Frejd, F.Y.; Nygren, P.Å.; Löfblom, J. Affibody Molecules in Biotechnological and Medical Applications. Trends Biotechnol. 2017, 35, 691-712. [CrossRef] [PubMed]

15. Sörensen, J.; Sandberg, D.; Sandström, M.; Wennborg, A.; Feldwisch, J.; Tolmachev, V.; Åström, G.; Lubberink, M.; Garske-Román, U.; Carlsson, J.; et al. First-in-human molecular imaging of HER2 expression in breast cancer metastases using the 111In-ABY-025 affibody molecule. J. Nucl. Med. 2014, 55, 730-735. [CrossRef] [PubMed]

16. Sörensen, J.; Velikyan, I.; Sandberg, D.; Wennborg, A.; Feldwisch, J.; Tolmachev, V.; Orlova, A.; Sandström, M.; Lubberink, M.; Olofsson, H.; et al. Measuring HER2-Receptor Expression In Metastatic Breast Cancer Using [68Ga]ABY-025 Affibody PET/CT. Theranostics 2016, 6, 262-271. [CrossRef] [PubMed]

17. Malm, M.; Kronqvist, N.; Lindberg, H.; Gudmundsdotter, L.; Bass, T.; Frejd, F.Y.; Höidén-Guthenberg, I.; Varasteh, Z.; Orlova, A.; Tolmachev, V.; et al. Inhibiting HER3-mediated tumor cell growth with affibody molecules engineered to low picomolar affinity by position-directed error-prone PCR-like diversification. PLOS ONE 2013, 8, e62791. [CrossRef]

18. Göstring, L.; Malm, M.; Höidén-Guthenberg, I.; Frejd, F.Y.; Ståhl, S.; Löfblom, J.; Gedda, L. Cellular effects of HER3-specific affibody molecules. PLoS ONE 2012, 7, e40023. [CrossRef] [PubMed]

19. Kronqvist, N.; Malm, M.; Göstring, L.; Gunneriusson, E.; Nilsson, M.; Höidén Guthenberg, I.; Gedda, L.; Frejd, F.Y.; Ståhl, S.; Löfblom, J. Combining phage and staphylococcal surface display for generation of ErbB3-specific Affibody molecules. Protein Eng. Des. Sel. 2011, 24, 385-396. [CrossRef] [PubMed] 
20. Malm, M.; Bass, T.; Gudmundsdotter, L.; Lord, M.; Frejd, F.Y.; Ståhl, S.; Löfblom, J. Engineering of a bispecific affibody molecule towards HER2 and HER3 by addition of an albumin-binding domain allows for affinity purification and in vivo half-life extension. Biotechnol. J. 2014, 9, 1215-1222. [CrossRef] [PubMed]

21. Rosestedt, M.; Andersson, K.G.; Mitran, B.; Tolmachev, V.; Löfblom, J.; Orlova, A.; Ståhl, S. Affibody-mediated PET imaging of HER3 expression in malignant tumours. Sci. Rep. 2015, 5, 15226. [CrossRef] [PubMed]

22. Andersson, K.G.; Rosestedt, M.; Varasteh, Z.; Malm, M.; Sandström, M.; Tolmachev, V.; Löfblom, J.; Ståhl, S.; Orlova, A. Comparative evaluation of 111In-labeled NOTA-conjugated affibody molecules for visualization of HER3 expression in malignant tumors. Oncol. Rep. 2015, 34, 1042-1048. [CrossRef] [PubMed]

23. Frejd, F. Half-Life Extension by Binding to Albumin through an Albumin Binding Domain. In Therapeutic Proteins: Strategies to Modulate Their Plasma Half-Lives; Kontermann, R., Ed.; Wiley-VCH Verlag GmbH \& Co.: Weinheim, Germany, 2012; pp. 269-283, ISBN 978-3-527-32849-9.

24. Jonsson, A.; Dogan, J.; Herne, N.; Abrahmsén, L.; Nygren, P.A. Engineering of a femtomolar affinity binding protein to human serum albumin. Protein Eng. Des. Sel. 2008, 21, 515-527. [CrossRef] [PubMed]

25. Frejd, F.; Klint, S.; Gudmundsdotter, L.; Höidén-Guthenberg, I.; Feldwisch, J.; Wennborg, A.; Bejker, D.; Reich, K. Blocking IL-17A with femtomolar affinity using the novel engineered Affibody ligand trap ABY-035: Interim results from a phase I, first in human study. In Proceedings of the 26th EADV Congress, Geneva, Switzerland, 13-17 September 2017.

26. Schardt, J.S.; Oubaid, J.M.; Williams, S.C.; Howard, J.L.; Aloimonos, C.M.; Bookstaver, M.L.; Lamichhane, T.N.; Sokic, S.; Liyasova, M.S.; O’Neill, M.; et al. Engineered Multivalency Enhances Affibody-Based HER3 Inhibition and Downregulation in Cancer Cells. Mol. Pharm. 2017, 14, 1047-1056. [CrossRef] [PubMed]

27. Bass, T.Z.; Rosestedt, M.; Mitran, B.; Frejd, F.Y.; Löfblom, J.; Tolmachev, V.; Ståhl, S.; Orlova, A. In vivo evaluation of a novel format of a bivalent HER3-targeting and albumin-binding therapeutic affibody construct. Sci. Rep. 2017, 7, 43118. [CrossRef] [PubMed]

28. Orlova, A.; Bass, T.Z.; Rinne, S.S.; Leitao, C.D.; Rosestedt, M.; Atterby, C.; Gudmundsdotter, L.; Frejd, F.Y.; Löfblom, J.; Tolmachev, V.; et al. Evaluation of the Therapeutic Potential of a HER3-Binding Affibody Construct TAM-HER3 in Comparison with a Monoclonal Antibody, Seribantumab. Mol. Pharm. 2018, 15, 3394-3403. [CrossRef] [PubMed]

29. Tolmachev, V.; Mume, E.; Sjöberg, S.; Frejd, F.Y.; Orlova, A. Influence of valency and labelling chemistry on in vivo targeting using radioiodinated HER2-binding Affibody molecules. Eur. J. Nucl. Med. Mol. Imaging 2009, 36, 692-701. [CrossRef] [PubMed]

30. Tolmachev, V.; Feldwisch, J.; Lindborg, M.; Baastrup, B.; Sandström, M.; Orlova, A. Influence of an aliphatic linker between DOTA and synthetic Z(HER2:342) Affibody molecule on targeting properties of the (111)In-labeled conjugate. Nucl. Med. Biol. 2011, 38, 697-706. [CrossRef] [PubMed]

31. Wållberg, H.; Orlova, A.; Altai, M.; Hosseinimehr, S.J.; Widström, C.; Malmberg, J.; Ståhl, S.; Tolmachev, V. Molecular design and optimization of $99 \mathrm{mTc}$-labeled recombinant affibody molecules improves their biodistribution and imaging properties. J. Nucl. Med. 2011, 52, 461-469. [CrossRef] [PubMed]

32. Altai, M.; Liu, H.; Orlova, A.; Tolmachev, V.; Gräslund, T. Influence of molecular design on biodistribution and targeting properties of an Affibody-fused HER2-recognising anticancer toxin. Int. J. Oncol. 2016, 49, 1185-1194. [CrossRef] [PubMed]

33. Wållberg, H.; Orlova, A. Slow internalization of anti-HER2 synthetic affibody monomer 111In-DOTAZHER2:342-pep2: Implications for development of labeled tracers. Cancer Biother. Radiopharm. 2008, 23, 435-442. [CrossRef] [PubMed]

34. Schoeberl, B.; Kudla, A.; Masson, K.; Kalra, A.; Curley, M.; Finn, G.; Pace, E.; Harms, B.; Kim, J.; Kearns, J.; et al. Systems biology driving drug development: From design to the clinical testing of the anti-ErbB3 antibody seribantumab (MM-121). NPJ Syst. Biol. Appl. 2017, 3, 16034. [CrossRef] [PubMed]

35. Yokota, T.; Milenic, D.E.; Whitlow, M.; Schlom, J. Rapid tumor penetration of a single-chain Fv and comparison with other immunoglobulin forms. Cancer Res. 1992, 52, 3402-3408. [PubMed]

36. Da Pieve, C.; Allott, L.; Martins, C.D.; Vardon, A.; Ciobota, D.M.; Kramer-Marek, G.; Smith, G. Efficient [(18)F]AlF Radiolabeling of ZHER3:8698 Affibody Molecule for Imaging of HER3 Positive Tumors. Bioconjug. Chem. 2016, 27, 1839-1849. [CrossRef] [PubMed] 
37. Lindzen, M.; Lavi, S.; Leitner, O.; Yarden, Y. Tailored cancer immunotherapy using combinations of chemotherapy and a mixture of antibodies against EGF-receptor ligands. Proc. Natl. Acad. Sci. USA 2010, 107, 12559-12563. [CrossRef] [PubMed]

38. Fitzgerald, J.B.; Johnson, B.W.; Baum, J.; Adams, S.; Iadevaia, S.; Tang, J.; Rimkunas, V.; Xu, L.; Kohli, N.; Rennard, R.; et al. MM-141, an IGF-IR- and ErbB3-directed bispecific antibody, overcomes network adaptations that limit activity of IGF-IR inhibitors. Mol. Cancer Ther. 2014, 13, 410-425. [CrossRef] [PubMed]

39. Liu, J.F.; Ray-Coquard, I.; Selle, F.; Poveda, A.M.; Cibula, D.; Hirte, H.; Hilpert, F.; Raspagliesi, F.; Gladieff, L.; Harter, P.; et al. Randomized Phase II Trial of Seribantumab in Combination with Paclitaxel in Patients with Advanced Platinum-Resistant or -Refractory Ovarian Cancer. J. Clin. Oncol. 2016, 34, 4345-4353. [CrossRef] [PubMed]

40. Barta, P.; Malmberg, J.; Melicharova, L.; Strandgård, J.; Orlova, A.; Tolmachev, V.; Laznicek, M.; Andersson, K. Protein interactions with HER-family receptors can have different characteristics depending on the hosting cell line. Int. J. Oncol. 2012, 40, 1677-1682. [CrossRef] [PubMed]

41. Hettmann, T.; Schneider, M.; Ogbagabriel, S.; Xie, J.; Juan, G.; Hartmann, S.; Radinsky, R.; Freeman, D.J. U3-1287 (AMG 888), a fully human anti-HER3 mAb, inhibits HER3 activation and induces HER3 internalization and degradation. Cancer Res. 2010, 70, LB-306. [CrossRef]

42. Hopp, J.; Hornig, N.; Zettlitz, K.A.; Schwarz, A.; Fuss, N.; Müller, D.; Kontermann, R.E. The effects of affinity and valency of an albumin-binding domain (ABD) on the half-life of a single-chain diabody-ABD fusion protein. Protein Eng. Des. Sel. 2010, 23, 827-834. [CrossRef] [PubMed]

43. Tolmachev, V.; Orlova, A.; Pehrson, R.; Galli, J.; Baastrup, B.; Andersson, K.; Sandström, M.; Rosik, D.; Carlsson, J.; Lundqvist, H.; et al. Radionuclide therapy of HER2-positive microxenografts using a 177Lulabeled HER2-specific Affibody molecule. Cancer Res. 2007, 67, 2773-2782. [CrossRef] [PubMed]

44. Orlova, A.; Jonsson, A.; Rosik, D.; Lundqvist, H.; Lindborg, M.; Abrahmsen, L.; Ekblad, C.; Frejd, F.Y.; Tolmachev, V. Site-specific radiometal labeling and improved biodistribution using ABY-027, a novel HER2-targeting affibody molecule-albumin-binding domain fusion protein. J. Nucl. Med. 2013, 54, 961-968. [CrossRef] [PubMed] 